Biota Vol. IX (3): 179-185, Oktober 2004 ISSN 0853-8670

\title{
Collembola Lantai Hutan Di Kawasan Hulu Sungai Tabalong Kalimantan Selatan
}

\author{
Collembola on forest floor in Upper Tabalong River, South Kalimantan
}

Cahyo Rahmadi ${ }^{*}$, Yayuk R. Suhardjono ${ }^{1}$, dan Iwing Andayani ${ }^{1}$

Bidang Zoologi Pusat Penelitian Biologi LIPI Cibinong

e-mail: cahyo.rahmadi@lipi.go.iddan yayukrs@indo.net.id.*Penulis untuk korespondensi

\begin{abstract}
Collembola in Kalimantan Island is poorly studied even this island has high value of biodiversity especially Collembola. Taxonomically, Collembola in Borneo was studied well by Yosii in Sabah (Malaysia) in the other side, very few report about ecology of Collembola in Kalimantan. This research was aimed to study the ecology of Collembola in five different forest types i.e. 3 natural forest and two Industrial tree plantation (HTI). This study was done in forest on Upper Tabalong River at June 2002. Collembola was collected by using a pitfall traps and soil-litter samples. Each forest type had twenty pitfall traps were set along two transects with 100 in length and operated for four days. Five soil-litter samples were collected in each forest type and modification of Berlese funnel was used to sort out Collembola from soil and litter for two weeks. The results of study show that dominant families in study sites are Paronellidae, Dicyrtomidae and Entomobryidae. These families are surface dwelling Collembola that live on soil surface among the litter. Five different forest types have different Collembolan composition due to different microhabitat, which had different vegetation and diversity. Number of species and individual of Collembola was showed that the highest of Collembola both species and individual was in natural forest (Km 57/Arboretum) and the lowest one was in Industrial tree plantation (HTI 1/Acacia mangium).The richness of collembola was affected by diversity of vegetation in each site and condition of forest floor.
\end{abstract}

Keywords: natural forest, industrial tree plantation, Collembola, South Kalimantan

Diterima: 9 Januari 2004, disetujui: 19 Maret 2004

\section{Pendahuluan}

Arthropoda tanah khususnya Collembola merupakan salah satu indikator kualitas lingkungan dan dapat dijadikan indikator kualitas hutan (Hopkins, 1997). Hasil penelitian ini diharapkan dapat menjadi salah satu pertimbangan pengelolaan hutan. Penelitian Arthropoda tanah di Kalimantan baru dilakukan di hutan Kalimantan Timur (Suhardjono, 1985), Kalimantan Tengah (Suhardjono, 2001; Rahmadi dan Suhardjono, 2002) dan Kalimantan Selatan (Suhardjono, 2001). Penelitian khusus meneliti tentang taksonomi Collembola baru dilakukan oleh
Yoshii (1981-1983) di Sabah (Malaysia) sedangkan di Indonesia (Kalimantan) belum banyak dilakukan baik taksonomi maupun ekologi.

Diharapkan data keanekaragaman Arthropoda tanah dari berbagai macam tipe pengelolaan hutan (seperti beda umur tebang dan jenis tanaman) dapat membantu sistem pengelolaan selanjutnya demi menjaga kelestarian biota tanah.

Collembola merupakan salah satu kelompok biota tanah yang mendominasi komunitas biota dilantai hutan. Kehadirannya dapat ditemukan di mana-mana. Di samping itu, perannya di dalam ekosistem tanah juga tidak dapat diabaikan. Collembola selain 
dikenal membantu proses perombakan bahan organik dan pembentukan tanah juga berperan sebagai penyeimbang ekosistem (Hopkins, 1997). Collembola juga dikenal sebagai salah satu biota yang dapat dimanfaatkan sebagai indikator keadaan tanah (Christiansen, 1964). Oleh karena itu keberadaan Collembola perlu diketahui dengan pasti sehingga pembahasan khusus mengenai Collembola perlu dilakukan untuk mengetahui status populasi di masingmasing tegakan. Bahasan mengenai Collembola ini dimaksudkan untuk mengetahui keanekaragaman spesies Collembola pada lantai lima tipe hutan yang berbeda. Diharapkan dari hasil yang diperoleh dapat memberi gambaran dan penyebab adanya perbedaan keanekaragaman dari lima tipe hutan yang diamati. Perbandingan perbedaan komunitas Collembola dari hasil penelitian ini diharapkan dapat dijadikan dasar kebijakan pengelolaan hutan di Kalimantan.

\section{Metode Penelitian}

\section{Lokasi}

Hutan di kawasan hulu Sungai Tabalong merupakan hutan produksi di bawah hak pengusahaan hutan PT AYI (PT Ayayang Indonesia) Perusahaan ini masih menyisakan hutan alami di beberapa tempat. Penelitian mengenai Collembola lantai hutan kawasan hulu sungai Tabalong dilakukan pada tanggal 12-29 Juni 2001 pada lima lokasi terpilih:

- Hutan di Kilometer 92: koordinat $1^{\circ}$ $32^{\prime} 20,7^{\prime \prime}$ LS dan $115^{\circ} 30^{\prime} 25,6^{\prime \prime}$ BT, ketinggian $216 \mathrm{~m}$ dpl., topografi lereng, kemiringan $50-60 \%$, areal tebangan tahun 2000, vegetasi didominasi oleh biwan (Leguminosae, Endertia spectabilis) yang berdiameter $>50 \mathrm{~cm}$, ada beberapa Dipterocarpaceae yang masih kecil, lantai hutan didominasi oleh sespesies perdu berduri, kanopi yang cukup rapat, serasah tebal dan lembab, cahaya matahari tidak mencapai lantai pH tanah 6,8 dan kelembaban 50\%.
- Hutan Kilometer 70: koordinat $1^{\circ} 32^{\prime}$ 20.7" LS, $115^{\circ} 28$ ' 30.5" BT, ketinggian tempat $216 \mathrm{~m} \mathrm{dpl.,} \mathrm{blok} \mathrm{penebangan}$ tahun 1996-1997, vegetasi didominasi oleh Dipterocarpaceae terutama Shorea sp. dengan diameter $<40 \mathrm{~cm}$, kanopi tidak terlalu rapat, tumbuhan bawah didominasi rotan, cahaya sedikit mencapai lantai hutan, $\mathrm{pH}$ 6,2 tanah, kelembaban $62 \%$, serasah cukup tebal dan lembab.

- Hutan Kilometer 57 (Arboretum) yang didominasi oleh Dipterocarpaceae terutama Shorea laevis dengan diameter $<50 \mathrm{~cm}$, mengalami gangguan penebangan liar, koordinat $1^{\circ} 44^{\prime} 22.6^{\prime \prime}$ LS dan $115^{\circ} 21^{\prime} 02.6^{\prime \prime} \mathrm{BT}$, ketinggian 213 m dpl., lantai hutan $\mathrm{pH} 5,9$, kelembaban $75 \%$, cahaya mencapai lantai hutan, serasah tebal didominasi serasah Dipterocarpaceae.

- Hutan Tanaman Industri (HTI) 1 Acacia mangium berumur 1 tahun dengan diameter $<15 \mathrm{~cm}$, tumbuhan bawah rapat dengan Imperata cylindrica dan Melastoma sp., lantai hutan dengan pH 6,1 dan kelembaban 54\%, koordinat $1^{\circ} 51^{\prime} 20.4^{\prime \prime}$ LS dan $115^{\circ} 21^{\prime} 2.6^{\prime \prime} \mathrm{BT}$, ketinggian $204 \mathrm{~m} \mathrm{dpl}$.

- Hutan Tanaman Industri (HTI) 2 dengan tanaman Albizia falcata berumur 7 tahun, koordinat $1^{\circ} 51^{\prime} 20.5^{\prime}$ LS dan $115^{\circ} 20^{\prime} 44.7$ " BT, ketinggian $204 \mathrm{~m}$ dpl., tumbuhan bawah rapat dengan Imperata cylindrica dan spesies Alpinia sp., lantai hutan dengan $\mathrm{pH} 6$ kelembaban 53\%, serasah terdiri dari daun bambu dan albizia yang sangat tebal dan lembab, cahaya matahari tidak mencapai lantai hutan.

\section{Pengumpulan Collembola}

Pengumpulan Collembola dilakukan dengan dua metode yaitu perangkap sumuran (untuk Collembola yang aktif di permukaan) dan cuplikan contoh tanah-serasah (untuk Collembola yang hidup di serasah dan tanah). Dua puluh perangkap sumuran dipasang pada dua jalur transek sepanjang 100 meter dengan 
jarak masing-masing 10 meter selama 4 hari. Perangkap yang digunakan berupa gelas plastik (berukuran diameter atas $7 \mathrm{~cm}$ dan diameter dasar $5 \mathrm{~cm}$ ) yang ditanam dengan permukaan atas gelas rata permukaan tanah. Gelas plastik diisi alkohol $96 \%$ setinggi $5 \mathrm{~cm}$ dan ditambah 5 tetes gliserin. Lima contoh tanah dan serasah dengan ukuran $0,5 \times 0,5$ meter sedalam $5 \mathrm{~cm}$ dikumpulkan. Collembola dipisahkan dari contoh tanah dan serasah dengan modifikasi corong Berlese selama 2 minggu tanpa menggunakan penerangan bolam lampu melainkan dengan suhu kamar.

\section{Hasil dan Pembahasan}

\section{A.Perbandingan komposisi Collembola di tiap lokasi}

Collembola yang didapatkan di hutan hulu Sungai Tabalong sebanyak 119 spesies dari 13 famili atau 2460 individu (Tabel 1). Famili yang paling melimpah adalah Paronellidae $(30,33 \%)$ di tempat kedua dan ketiga yaitu Dicyrtomidae $(19,80 \%)$ dan Entomobryidae (11,99\%) (Tabel 1). Sementara famili yang paling banyak spesiesnya adalah Paronellidae (46 spesies). Sebaliknya famili yang paling sedikit jumlah individu maupun jumlah spesiesnya adalah Odontellidae dan Onychiuridae yang tidak mencapai $1 \%$ dari total famili anggota Collembola di hulu Sungai Tabalong.

Masing-masing lokasi mempunyai komposisi Collembola yang berbeda-beda dan famili yang dominan juga berbeda (Tabel 1). Di lokasi Km 92 didominasi oleh Paronellidae $(57,21 \%)$, Entomobryidae $(17,91 \%)$ dan Brachystomellidae (7,13\%). Km 70 didominasi oleh Dicyrtomidae (58,29\%), Paronellidae $(12,05 \%)$ dan Entomobryidae $(9,07 \%)$.
Komposisi Collembola di Km 57 didominasi oleh Hypogastruridae $(23,12 \%)$, Paronellidae $(22,36 \%)$ dan Cyphoderidae (22,21\%). Lokasi HTI I didominasi oleh Paronellidae (46,47\%), Isotomidae $(37,65 \%)$ dan Entomobryidae $(10,00 \%)$. Sedangkan HTI 2 didominasi oleh Isotomidae $(30,58 \%)$, Paronellidae $(24,76 \%)$ dan Entomobryidae (14,56\%) (Gambar 1 dan Tabel 1). Di kelima lokasi terdapat tujuh famili yang mendominasi komposisi Collembola yaitu Entomobryidae, Paronellidae, Brachystomellidae, Dicyrtomidae, Hypogastruridae, Cyphoderidae dan Isotomidae dengan komposisi yang berbeda-beda pada tiap-tiap lokasi. Komposisi famili di tiap-tiap lokasi ditunjukkan pada Gambar 1 dan Tabel 1.

Kawasan hutan Hulu Sungai Tabalong didominasi oleh Collembola dari famili Paronellidae, Dicyrtomidae dan Entomobryidae. Ketiga famili dominan ini merupakan Collembola yang aktif di permukaan. Hal tersebut dapat dilihat dari ciri morfologi yang khas untuk kelompok yang hidup di permukaan tanah yaitu berukuran tubuh besar, berpigmen, antena dan furka berkembang baik (panjang). Kondisi ini menunjukkan bahwa lantai hutan di Hulu Sungai Tabalong sesuai untuk Collembola permukaan. Collembola permukaan tanah melimpah di lantai hutan yang mempunyai lapisan serasah tebal. Semua lokasi tegakan di hutan hulu Sungai Tabalong masih mempunyai lapisan serasah yang tebal. Sementara Collembola yang hidup di dalam tanah seperti Isotomidae dan Onychiuridae ditemukan dalam jumlah tidak banyak. Berdasarkan jumlah spesies di Hulu Tabalong lebih tinggi dibandingkan dengan Hulu Katingan di Kalimantan Tengah (103 spesies, 13 famili 3372 individu) (Rahmadi dan Suhardjono 2002) namun berdasarkan jumlah individu relatif lebih sedikit. 
Tabel 1. Kemelimpahan relatif (\%) famili di tiap lokasi

\begin{tabular}{|c|c|c|c|c|c|c|c|c|c|}
\hline \multirow{2}{*}{ No. } & \multirow{2}{*}{ Famili } & \multirow{2}{*}{$\begin{array}{c}\text { Jml } \\
\text { spesies }\end{array}$} & \multicolumn{5}{|c|}{ Lokasi } & \multirow{2}{*}{$\begin{array}{l}\text { Total } \\
\text { ind. }\end{array}$} & \multirow{2}{*}{$\begin{array}{c}\text { Total } \\
\text { Relatif } \\
(\%)\end{array}$} \\
\hline & & & Km 92 & Km 70 & Km 57 & HTI 1 & HTI 2 & & \\
\hline 1 & Paronellidae & 46 & 57.21 & 12.05 & 22.36 & 46.47 & 24.76 & 746.00 & 30.33 \\
\hline 2 & Dicyrtomidae & 5 & 2.88 & 58.29 & 2.30 & 1.18 & 0.49 & 487.00 & 19.80 \\
\hline 3 & Entomobryidae & 12 & 17.91 & 9.07 & 9.19 & 10.00 & 14.56 & 295.00 & 11.99 \\
\hline 4 & Cyphoderidae & 7 & 0.61 & 7.38 & 22.21 & 2.91 & 13.11 & 238.00 & 9.67 \\
\hline 5 & Isotomidae & 13 & 0.76 & 5.18 & 9.49 & 37.65 & 30.58 & 234.00 & 9.51 \\
\hline 6 & Hypogastruridae & 6 & 7.13 & 0.52 & 23.12 & 0.59 & 1.94 & 207.00 & 8.41 \\
\hline 7 & Sminthuridae & 18 & 2.88 & 6.48 & 4.44 & 0.00 & 12.14 & 123.00 & 5.00 \\
\hline 8 & Brachystomellidae & 3 & 7.13 & 0.13 & 4.90 & 0.00 & 0.49 & 81.00 & 3.29 \\
\hline 9 & Neanuridae & 3 & 2.88 & 0.26 & 0.31 & 1.18 & 0.49 & 26.00 & 1.06 \\
\hline 10 & Neelidae & 3 & 0.61 & 0.39 & 1.07 & 0.00 & 1.46 & 17.00 & 0.69 \\
\hline 11 & Tomoceridae & 1 & 0.00 & 0.00 & 0.46 & 0.00 & 0.00 & 3.00 & 0.12 \\
\hline 12 & Odontellidae & 1 & 0.00 & 0.13 & 0.15 & 0.00 & 0.00 & 2.00 & 0.08 \\
\hline \multirow[t]{2}{*}{13} & Onychiuridae & 1 & 0.00 & 0.13 & 0.00 & 0.00 & 0.00 & 1.00 & 0.04 \\
\hline & Jumlah & & 100 & 100 & 100 & 100 & 100 & 2460.00 & 100 \\
\hline
\end{tabular}

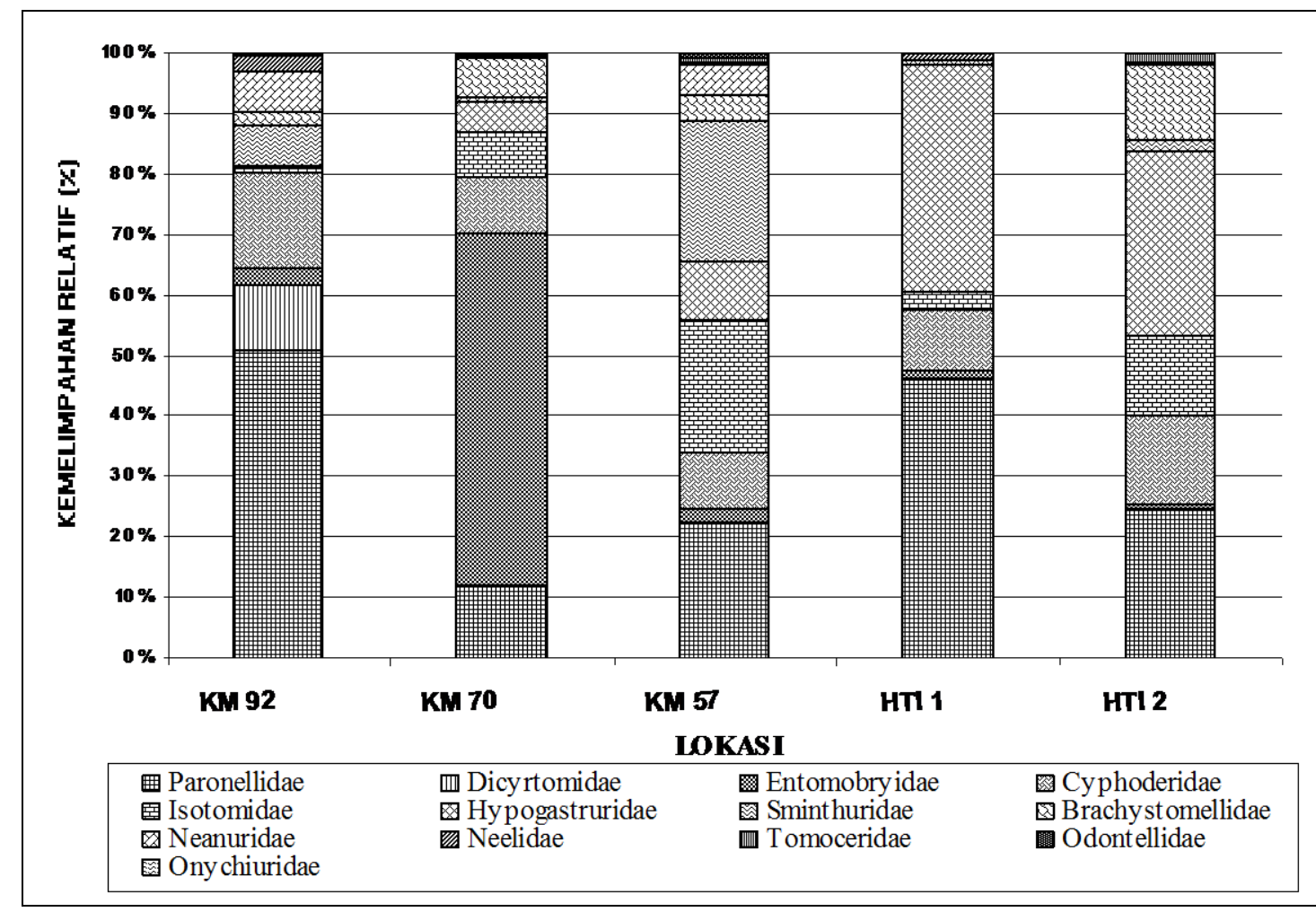

Gambar 1. Perbandingan komposisi Collembola di tiap lokasi

Komposisi Collembola dan famili yang dominan di tiap lokasi terdapat perbedaan dan hal ini diduga dikarenakan perbedaan vegetasi dan kondisi mikro habitat masing-masing lokasi. Di tegakan hutan $\mathrm{Km} \mathrm{92,} \mathrm{lebih} \mathrm{dari}$ $50 \%$ komposisi Collembola didominasi oleh
Paronellidae sedangkan famili yang lain hanya menyumbang tidak lebih dari $20 \%$ komposisi Collembola. Hal yang sama juga terdapat di $\mathrm{Km} 70$ dimana Dicyrtomidae mendominasi lebih dari $50 \%$ komposisi Collembola dan famili yang lain masing-masing tidak lebih dari 
$12 \%$. Tingginya dominasi salah satu famili akan menyebabkan famili lain menjadi rendah karena tingginya kompetisi. Lokasi di Km 92 dan $\mathrm{Km} 70$ mempunyai hutan yang masih bagus dengan kanopi rapat dan serasah tebal di lantai hutannya. Kondisi serasah tebal dan lembab menyediakan kondisi mikrohabitat yang cocok untuk Collembola permukaan seperti Paronellidae. Sebaliknya di HTI 1 dan HTI 2, Collembola permukaan relatif kecil dan dominasinya tidak mencapai 50\% (Tabel 1) justru Isotomidae di kedua lokasi in mempunyai kemelimpahan yang lebih tinggi di bandingkan di Km 92 dan Km 70. Hal ini menunjukkan bahwa kondisi hutan di HTI sesuai untuk Isotomidae. Kondisi tegakan di HTI 1 dan HTI 2 mempunyai keanekaragaman vegetasi yang rendah karena hanya ditanami Acacia mangium dan Albizia falcata saja, sedangkan kondisi lantai hutan hanya didominasi oleh serasah yang tidak beragam. Kemelimpahan Isotomidae di HTI untuk dijadikan sebagai indikator perubahan kualitas hutan masih memerlukan penelitian yang lebih lanjut dan pemantauan yang berkelanjutan. Di hutan $\mathrm{Km} 57$ dari tiga famili yang melimpah mempunyai kemelimpahan relatif yang hampir sama, tidak ada famili yang menonjol dan dominan Kemelimpahan masing-masing famili yang dominan tidak lebih dari $23 \%$ dan yang paling tinggi adalah Hypogastruridae
$(23,12 \%)$ yang mempunyai morfologi khas permukaan namun organ peloncatnya (furca) telah mereduksi sehingga Hypogastruridae mempunyai mobilitas yang sangat rendah. Hypogastruridae sangat mudah terancam oleh predator Collembola karena kemampuan untuk menghindar dari predator sangat rendah. Komposisi Collembola di Km 57 mempunyai kemantapan yang rendah sehingga perubahan komposisi masih bisa terjadi jika ada perubahan lingkungan seperti meningkatnya keberadaan predator atau meningkatnya penebangan liar di Km 57.

\section{B. Keanekaragaman Collembola}

Berdasarkan kemelimpahan individu Collembola di tiap lokasi, ternyata yang paling melimpah adalah Km 70 (772 individu) dan paling kecil adalah HTI I (170 individu). Kekayaan spesies paling tinggi adalah Km 57 dan terkecil adalah HTI I (Tabel 2). Sedang tiga lokasi lain berbeda yaitu Km 92 (659 individu), Km 57 (657 individu) dan HTI 2 (206 individu)

Berdasarkan jumlah spesies dan famili, lokasi yang paling kaya adalah hutan di Km 57 yaitu 72 spesies dari 12 famili. Sedangkan yang paling sedikit adalah di HTI 1, 27 spesies dari 7 famili) (Tabel 2).

Tabel 2. Jumlah individu, spesies dan famili Collembola di tiap lokasi

\begin{tabular}{lccccc}
\hline \multirow{2}{*}{ Jumlah } & \multicolumn{5}{c}{ LOKASI } \\
\cline { 2 - 6 } & Km 92 & Km 70 & Km 57 & HTI 1 & HTI 2 \\
\hline \hline Individu & 659 & 772 & 657 & 170 & 206 \\
Spesies & 67 & 47 & 72 & 27 & 35 \\
Famili & 10 & 12 & 12 & 7 & 10 \\
\hline
\end{tabular}

Berdasarkan jumlah spesies dan jumlah individu, lokasi yang paling tinggi jumlah spesiesnya adalah Km 57 (Arboretum) namun mempunyai jumlah individu yang lebih kecil dibandingkan $\mathrm{Km}$ 70. Hal ini diduga disebabkan oleh adanya tingkat kompetisi antar spesies yang tinggi sehingga kemelimpahan individu masing-masing spesies rendah
Sebaliknya semakin sedikit jumlah spesies semakin tinggi jumlah individunya karena tingkat kompetisi yang rendah. Seperti yang ditemukan di $\mathrm{Km} \mathrm{70,} \mathrm{di} \mathrm{antara} 3$ hutan yang masih alami Km 70 mempunyai jumlah spesies paling kecil namun mempunyai jumlah individu yang paling besar. 
Lokasi hutan yang telah diubah menjadi hutan monokultur menunjukkan jumlah spesies maupun jumlah individu yang kecil dibanding 3 lokasi di hutan yang relatif masih alami. Rendahnya jumlah spesies maupun jumlah individu diduga dapat disebabkan rendahnya variasi pakan di HTI 1 dan HTI 2 karena hanya berasal dari serasah Acacia mangium maupun Albizia falcata. Walaupun ada tumbuhan bawah yang menutup lantai hutan yaitu adanya Imperata cylindrica, Melastoma dan Alpinia sp namun serasah yang dihasilkan pun masih belum bervariasi dan mempunyai kecenderungan serasahnya lebih keras dan kering sehingga lebih lama mengalami dekomposisi.

Keanekaragaman vegetasi secara tidak langsung berpengaruh pada keanekaragaman Collembola karean semakin tinggi keanekaragaman vegetasi akan semakin bervariasi pakan yang tersedia. Semakin tinggi variasi pakan akan semakin beragam hewan yang mengkonsumsi. Perubahan hutan alami menjadi hutan tanaman indusrti telah merubah kondisi mikrohabitat karena menurunnya variasi pakan dan perubahan kondisi fisik kimia tanah karena dipengaruhi oleh kondisi serasah yang bukan dari tanaman asli tempatan. Sehingga hanya Collembola yang toleran terhadap perubahan kondisi mikrohabitat saja yang bertahan dan mendominasi, sementara Collembola yang tidak toleran akan menghindar atau bahkan punah.

\section{Kesimpulan}

Collembola di hulu Tabalong didapatkan sebanyak 119 spesies, 13 famili dan 2460 individu. Famili yang paling melimpah adalah Paronellidae, Dicyrtomidae dan Entomobryidae. Lokasi hutan yang paling tinggi keanekaragamannya adalah $\mathrm{Km} 57$ (arboretum) dan yang paling rendah HTI I (Acacia mangium). Tingginya keanekaragaman Collembola di $\mathrm{Km} 57$ disebabkan oleh keanekaragaman vegetasi yang masih tinggi sedangkan di HTI I mempunyai keanekaragaman vegetasi rendah karena merupakan hutan monokultur yang didominasi oleh Acacia mangium.

\section{Ucapan Terima Kasih}

Penulis mengucapkan terima kasih kepada Kepala Bidang Zoologi, Puslit Biologi LIPI atas ijin sehingga terlaksanaanya penelitian ini, Kepala Laboratorium Entomologi atas fasilitas laboratorium yang telah memungkinkan selesainya penelitian ini. Kepada SCKPFP (South and Central Kalimantan Production Forest Project)European Union yang telah mendanai penelitian ini dan staf di Banjar Baru, Alfan Subekti M,Sc. dan Ririen SP atas kerjasamanya selama di lapangan.

\section{Daftar Pustaka}

Cranston, P. 1990. Biomonitoring and Invertebrate taxonomy. Environmental Monitoring and Assessment $14: 265-273$.

Cranston, P. and Hilman, T. 1992. Rapid assessment of biodiversity using "Biological Diversity Technicians". Australian Biologist 5(3): 144154

Christiansen, K. 1964. Bionomic of Collembola. Ann Rev. Ent. 9: 147-178

Hopkins, S.P. 1997. Biology of the springtail (Insect: Collembola). Oxford University Press, Tokyo: 330

Rahmadi, Cahyo dan Suhardjono, Y.R. 2002 Keanekaragaman Arthropoda tanah di Lantai Hutan Kawasan Hulu Sungai Katingan Kalimantan Tengah. Abstrak. Program dan Makalah Seminar Aktivitas Penelitian Program Konservasi Keanekaragaman Hayati Biodiversity Conservation Project LIPI-JICAPHKA. Bogor 26-27 Juni 2002: 20

Suhardjono, Y.R. 1982. Beberapa kelompok Entomobryidae di lantai hutan Wanariset, Kalimantan Timur. Dalam Djajasasmita, M. \& G.G. Hambali (Ed.) Laporan Teknik Penelitian dan Pengembangan Sumberdaya Hayati, LGN LIPI, Bogor 1981-1982; 176-181.

Suhardjono, Y.R. 1985.Perbandingan Populasi Serangga Permukaan lantai Hutan Wanariset, Kalimantan Timur. Berita Biologi 3 (3): 104 - 107.

Suhardjono, Y.R. 1989. Revised Checklist of Collembola from Indonesia and its Adjacent region. AZAO 1: $1-22$. 
Rahmadi, et al.

Suhardjono Y.R. 2001. Laporan Survai: Penaksiran cepat keanekaragaman Invertebrata tanah di HPH PT Ayi Forest Production, Hulu Tabalong, Kalimantan Selatan. Balitbang Zoologi, Agustus 200126 pp.

Wallwork, J A 1976. The distribution and diversity of soil fauna. Academic Press Inc., London: 355 pp.

Yoshii, R. 1981. Neanurid Collembola of Sabah. Entomological Report from the Sabah Forest Research Centre.No. 3. Paronellid Collembola of Sabah. No. 4. Japan International Cooperatian Agency. EX-1 JR, 81-12: 1-70.
Yoshii, R. 1982. Lepidocyrtid Collembola of Sabah Entomological Report from the Sabah Forest Research Centre. No. 5. Yoshii, R. 1982. Studies on the Collembolan Genus Callyntrura and Dicranocentroides. Entomological Report from the Sabah Forest Research Centre. No. 6. from the Sabah Forest Research Centre. No. 6.
Japan International Cooperatian Agency: 1-38.

Yoshii, R. 1983. Studies on Paronellid Collembola of East Asia. Entomological Report from the Sabah Forest Research Centre. No. 7. Japan International Cooperatian Agency: 1-28.

Yudhistira, M., Suhardjono, Y.R. dan Duryadi, D. 1997. Perbandingan Populasi Serangga Tanah Pada Tiga Komposisi Tegakan Dipterocarpaceae. Pros. Seminar Biol. XIV \& Kongres Nas. Biol. XI 2: 85-90 